\title{
UNIVERSUM
}

I0.4067/So718-23762021000100273

\section{HETEROGENEIDAD Y DIFERENCIA EN LOS PENSAMIENTOS DE EMMANUEL LÉVINAS Y JACQUES DERRIDA}

\section{Heterogeneity and Difference in the thoughts of Emmanuel Lévinas and Jacques Derrida}

\section{Francisco Viguera Brante ${ }^{\text {iD }}$ \& Juan Ignacio Arias Krause ${ }^{2}$ (iD}

Investigador Independiente franciscoviguera@gmail.com

${ }^{2}$ Universidad Católica Silva Henríquez, Instituto de Filosofía, Santiago, Chile. Doctor en Filosofía.

\section{पख}

\section{RESUMEN}

El objetivo de este artículo es abordar la recepción realizada por Jacques Derrida respecto de la hospitalidad ética de Emmanuel Lévinas, con el fin de reevaluar la importancia de la alteridad levinasiana en la concepción derrideana de la diferencia. Para ello, el trabajo se divide en dos momentos: el primero examina la aporía de la deconstrucción que desarrolló Derrida, sobre la tensión entre violencia y hospitalidad; el segundo, sondea la fractura que abre el Otro en el pensamiento de Lévinas, mostrando el fondo y el límite en el que se mueve la aporía derrideana. De esta manera, y gracias a ambos planteamientos, se logra evidenciar que en sus núcleos acontece una heterogeneidad ética.

PALABRAS CLAVE: Emmanuel Lévinas; Jacques Derrida; heterogeneidad; diferencia; hospitalidad.

\section{ABSTRACT}

The objective of this article is to approach the reception made by Jacques Derrida regarding the ethical hospitality of Emmanuel Lévinas, in order to reevaluate the importance of Levinasian alterity in the Derridean conception of difference. For this, the work is divided into two moments: the first examines Derrida's aporia of deconstruction, on the tension between violence and hospitality; the second probed the fracture that the Other opens in Lévina's thought, showing the depth and the limit in which the Derridean aporia moves. Evidencing that an ethical heterogeneity occurs at the core of both approaches.

KEYWORDS: Emmanuel Lévinas; Jacques Derrida; heterogeneity; difference; hospitality. 


\section{INTRODUCCIÓN}

Lévinas reivindica la relación ética como principio irreductible de lo humano, argumentando su primado conforme a una exterioridad respecto de una violencia constitutiva. La significación de esa exterioridad se alimenta de una fuente heterogénea al logos. Lo que motiva el presente trabajo es una relación entre el Mismo y el Otro ${ }^{1}$ que no diluya la autonomía ni la identidad, pero tampoco aquella heterogeneidad que se encuentra en la base de la ética de la hospitalidad, es decir, la posibilidad de la justa relación entre los valores éticos de autonomía y relación, en vistas a la formación de una sociedad universal basada en principios éticos que no conculquen las diferencias culturales, ni individuales. La tesis que dirige este artículo es que la categoría de relación en Derrida obtiene su modelo en la ética de la hospitalidad de Lévinas, en tanto que esta permite la relación entre lo heterogéneo, evitando la guerra propuesta por la oposición lógica. Abriendo la posibilidad de repensar la deuda que tiene Derrida respecto del pensamiento levinasiano sobre la alteridad.

Si bien existen diferencias entre ambos pensadores - la deconstrucción derrideana responde a un pensamiento que se mueve en los límites del logos, pero desde el logos, mientras que el Otro trasciende infinitamente esos límites-, la deconstrucción y el Otro formulan a su modo las mismas aporías y proponen las mismas exigencias.

Para pensar más allá de la in-diferencia deben replantearse las categorías de relación y diferencia. Los problemas infinitos que produce la aporía (Derrida, I992: I42) pueden resumirse en el concepto de una relación sin relación, lo que requiere asumir las diferencias, no como diferencias -a fin de no perder la relación, homogenizando las diferencias-, sino como heterogeneidades; a fin de cuentas, la heterogeneidad que acontece en la relación ética es causa de la posibilidad de la diferencia lógica, como también de la hospitalidad.

En la primera parte se expondrá el problema de la aporía de la hospitalidad, la cual encarna un modo especial del problema de pensar el medio de la relación. El hiato que se produce entre los "extremos" relacionados deja la relación sin un punto de apoyo, lo que por una parte nos pone delante una lectura aporética y, por otra, abre múltiples posibilidades del pensar. La aporía se funda en una relación que se mantiene sin que haya algún punto de comparación. Toda relación requiere un medio en el cual relacionarse, si este medio es considerado desde el punto de vista lógico, lo entendemos como regla o criterio que nos permite relacionar, diferenciar, distinguir,

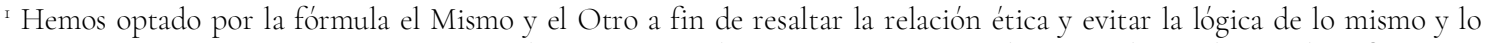
otro; y decidido omitir el problema de género que podría evitarse poniendo la/el misma/o y la/el otra/o a fin de no entorpecer la lectura (N. del A.).
} 
discernir, criticar, etc. La imposibilidad o aporía lógica de relacionar lo indiscernible solo puede resolverse haciendo, al mismo tiempo, al uno parte del otro, donde se encuentra el fondo de aquella fuerza o violencia originaria (Derrida, 1992) que está a la base del derecho - y del logos- en tanto que "parten" o unen lo que en sí mismo queda absuelto de cualquier relación lógica, o de derecho.

En la segunda parte, se verá cómo el pensamiento de Lévinas intenta desarrollarse fuera de toda dialéctica, que exponga al Otro en una relación mediada por la razón o la ley. El otro se expone desde su alteridad intransitable, aconteciendo desde un más allá, solo puede acogérsele "conforme a una suscepción más pasiva —o de otra manera- que la receptividad, la pasión y la finitud" (Pintor-Ramos, en Lévinas, 1987b: 42); aquella receptividad (sensibilidad)² que el pensamiento occidental subsumió debajo del logos y de sus leyes. El acoger al Otro invoca la necesidad de una suspensión de aquellos, a fin que este pueda alojarse más acá de los límites impuestos. Sin embargo, ni el logos ni la ley soberana pueden dejar sus mandatos al momento de "acoger" al otro desde la identidad soberana, imponiéndole por lo general las leyes "de la casa".

Por último, la conclusión mostrará las posibilidades de pensar en un futuro pacífico y realmente sustentable, donde el desarrollo de la hospitalidad pueda abrir paso a la idea de bien y a su realización en el tiempo y en la historia.

\section{LA DECONSTRUCCIÓN COMO POSIBILIDAD DE LA JUSTICIA}

Derrida aborda el tema de la hospitalidad en un complejo entramado de diversos textos de distintas décadas, que, si bien estos se hallan principalmente en diálogo con Emmanuel Lévinas, también puede rastrearse una "deconstrucción de la metafísica de la presencia de Husserl, Freud y Heidegger", como expone Herrero siguiendo a De Ville (Herrero, 2018: 82-83). Dentro del marco general de lecturas que siguen de cerca la recepción que Derrida hace de Lévinas en torno a la hospitalidad, pueden identificarse distintos momentos, que van desde el rechazo, pasando por la acogida, hasta la transformación radical. A pesar de los distintos matices o entonaciones ${ }^{3}$ de los diferentes momentos de la relación, incluso a pesar de la transformación radical que plantea De Ville (20II), Lévinas sigue apareciéndonos como un referente obligatorio en la lectura de Derrida.

El trabajo de Biset (2007), Jacques Derrida, entre violencia y hospitalidad, en torno de este mismo problema es ilustrador, pues muestra los distintos momentos imbricados punto por punto, y

\footnotetext{
2 "En efecto; las insuficiencias del plano consciente derivan de su inserción en la sensibilidad originaria, cuya pasividad es irreductible" (Pintor-Ramos, en Lévinas, 1987b: 30).

3 "La cuestión es la entonación de los textos de Derrida" (Biset, 2007: 133).
} 
los dispone tal como aparece en la bibliografía de Derrida, dejando ver como este desarrolla distintas entonaciones de lectura, entre una violencia irreductible y una hospitalidad irreductible; insertando luego esta tensión dentro de la tradición de discurso de la filosofía política (Biset, 2007: I3I). ${ }^{4}$ Los submomentos de estas variaciones de entonación son explicados por Biset con una notable claridad. Finitud, violencia y lenguaje se enredan en el primero de los extremos de la cuerda: ${ }^{2}$

En síntesis, en sus primeros textos, Derrida cuestiona la posibilidad de relacionarse con un absolutamente otro, y lo cuestiona desde tres lugares; primero, esa relación con el otro siempre se da en la escritura y no en la plenitud del habla; segundo, toda relación de exterioridad se da en un lenguaje; tercero, para evitar una violencia hacia el otro solo se puede apelar a una economía de la violencia. El primer Derrida cuestiona la infinitud levinasiana desde una finitud radical, señalando que lo que hay que hacer es reinventar el logos griego y no apelar a una salida de él. Y esta reinvención solo se da en una economía de la guerra. (Biset, 2007:135).

El momento intermediario - destacado con el latinismo excursus - se repliega sobre el lenguaje y enhebra los elementos de la differánce y la huella levinasiana, desplegando el problema de la contaminación (Biset, 2007: 136-137) - desde el cual Derrida se distanciaría de Lévinas- para elaborar un modo particular de tensión entre los extremos relacionados:

El problema puede enunciarse de este modo: si lo otro contamina lo uno, ¿cómo es posible su diferenciación? Cuestión de límites. Pero si se lee un autor y se señalan diferentes posicionamientos, aún más, se muestra una tensión entre esas dos posiciones, la cuestión es cómo pensar esto y no caer en un esquema cerrado. (Biset, 2007: I36).

\footnotetext{
4 "Existe una tradición que sitúa lo político en un campo de fuerzas que no puede ser regulado por una instancia superior y otra tradición que sitúa lo político justamente en la regulación de ese conflicto. Esta última tradición es posible dividirla entre aquellos que regulan el conflicto político desde una instancia propiamente política, por ejemplo la soberanía, y aquellos que regulan el conflicto desde una instancia externa a la política, una postura generalmente ética" (Biset, 2007: 132). Biset no considera la regulación jurídica en este esquema, por ejemplo, la del Derecho Internacional. A partir de ella podemos plantear nuestro distanciamiento respecto de su lectura, por ser esta disciplina jurídica, a nuestro juicio, un elemento fundamental dentro del campo de fuerzas que, para la filosofía moderna (la línea que va desde Hobbes a Schmitt, pasando por Hegel), constituye el momento otro de lo político o, posiblemente, donde lo político acontece en su real dimensión, frente a la cual tanto Derrida como Lévinas se distanciarían de manera radical. Lo propio hacemos nosotros, asumiendo la teoría de estos dos filósofos y cierta tradición jurídica Latinoamericana para la cual el Derecho internacional debería estar regido en base al Derecho de interdependencia y al interés general (cf. Álvarez, I94I, 1944, 1962). Para ser más precisos, el Derecho de interdependencia tiene el deber de limitar la soberanía, por lo que debería existir una regulación que al mismo tiempo fuese política, jurídica y ética, además social y psicológica. Desde este punto de vista, la ética y la política no deberían ser heterogéneas. Este no es un postulado exclusivamente ético, sino sobre todo jurídico, entendido en un sentido amplio, donde confluyen, junto con lo ético, también lo político, lo social y lo psicológico. No se trata, como sostiene Biset, de que lo ético sea externo a lo político. Eso solo sucede donde y cuando se desata la lucha de poder que no considera la necesidad de interdependencia como necesaria. Ahí toda regulación se vuelve asimétrica, por lo que no es política, en el sentido que no se ocupa del todo, sino de una soberanía cada vez más restringida, atomizada, individualista y egoísta. Por el contrario, la simetría en una ordenación jurídica como la planteada, no anula la heterogeneidad ética sino que la sostiene en y como forma política.

5 Biset asume que es el lenguaje el lugar donde se da la distancia entre ambos autores (134); desde ahí puede relacionarse la violencia del lenguaje con la producción de diferencias: "El lenguaje es escritura o differánce: la instancia que da origen a las diferencias" (Biset, 2007: 135). Esta diferencia no es la heterogeneidad en que distinguiremos al Mismo y al Otro en el medio de la relación ética, a fin de evitar la violencia entre ellos.
} 
En el segundo extremo de la cuerda se da la acogida, la hospitalidad a Lévinas, pero al mismo tiempo se plantea el tema que guía el Adiós a Emmanuel Lévinas: "la relación entre una ética de la hospitalidad y una política de la hospitalidad" (Biset, 2007: 138), mostrando la imposibilidad de establecer un medio que regule la relación entre ambas. Esto será reconocido en este trabajo dentro del problema de la heterogeneidad entre ambos órdenes, el punto en donde salta el quicio de la relación: ${ }^{6}$

Si en el primer caso introducía la política en el corazón de la ética, en esta lectura parece señalar la necesidad de cierta heterogeneidad de ambos órdenes. Esa heterogeneidad tiene que ver con toda una serie de textos escritos por Derrida en las últimas décadas donde se acerca a la idea de hospitalidad levinasiana como el lugar para pensar una ética actual. Un indicio de ello es la identificación de Derrida con la idea de justicia levinasiana como relación con el otro. Ese vínculo señala el lugar de una apertura incondicional hacia lo que viene, es decir, hacia el acontecimiento. Esta heterogeneidad debe complementarse con una necesidad, pues esa hospitalidad ética necesita de una política y un derecho para realizarse. Ese doble vínculo, heterogéneo y necesario, parece ser el eje central de la reflexión derrideana. (Biset, 2007: I38).

Biset (2007: 139) da cuenta de la necesidad de una deconstrucción de las condicionalidades en torno a la hospitalidad, a la apertura a la otredad y al acontecimiento, como uno de los elementos radicales de la teoría del segundo Derrida. En este sentido Lévinas no sería meramente un referente que sirve para leer la filosofía de Derrida, como desliza Biset en las primeras líneas de su texto. La idea de justicia levinasiana es exigida, como una apertura incondicional hacia lo que viene (del exterior), esta apertura incondicional, su acontecimiento, forma parte de la huella de Lévinas en Derrida, una huella que transita y contamina sus pensamientos haciéndolos parte de una tensión. La cual centraremos desde aquí en el lenguaje: "La escritura derrideana se opone a la alteridad absoluta levinasiana, siempre se dice al otro en el lenguaje" (Biset, 2007: 135). Esto expone la necesidad de la deconstrucción - hay que deconstruir para que pueda acontecer el Otro-, pero también ayuda a entender por qué la deconstrucción es la justicia. Entre estos términos hay una identidad fuerte, no se altera invirtiendo su posición, pues también la justicia es la deconstrucción. Sin embargo, tanto el Otro como la justicia sintonizan una heterogeneidad ante la cual a la deconstrucción no le queda más que acudir al recurso de oposiciones taxativas que intentan limitar

\footnotetext{
6 "El hiato, el silencio de esta no-respuesta acerca de los esquemas entre lo ético y lo político permanece. Es un hecho que permanece, y este hecho no es una contingencia empírica, es un Faktum. Pero debe también permanecer entre la promesa mesiánica y la determinación de una regla, de una norma o de un derecho político. Indica una heterogeneidad, una discontinuidad entre dos órdenes... (Derrida, 1998b: 147)" (tomado de: Biset, 2007: 138).

7 Esto está dicho en un doble sentido, explícitamente de la huella de Lévinas en Derrida, pero implícitamente de la huella desde donde se entiende la contaminación entre "un interior y un exterior, entre lo Mismo y lo Otro" (Guille, 2015: 266), de lo cual se sigue el problema de la presencia/ausencia: "Es debido al carácter que reviste el juego de la huella y la differánce que toda presencia habrá sido atravesada por una ausencia, y que toda supuesta mismidad se encuentra desde siempre excedida y desbordada por una alteridad constitutiva. Es a partir de este pensamiento de la huella y la differánce que se produce un desdibujamiento del límite preciso entre dos ámbitos que se resguardarían en su pureza. Para Derrida existe una contaminación originaria entre ambos" (Guille, 2015: 266).
} 
un significado, decir algo, de algo que no puede ser dicho, de ahí que el pensamiento vaya cayendo en aporías.

La deconstrucción de las condicionalidades disimula de un modo particular la otredad levinasiana, en cuanto que es esta la que aparece traicionada cuando se la enmarca dentro de cualquier esquema, legal o lógico; de ahí que la deconstrucción sea necesaria para que aparezca la justicia en el proceso legal y en la significación ${ }^{8}$ del Otro en el medio de la relación ética. ${ }^{9}$ La deconstrucción simula a su modo la otredad levinasiana, pero la absorbe rechazando la idea de separación absoluta, desde la idea de una contaminación originaria, que se desenvuelve en el medio del lenguaje. La significación que la deconstrucción puede ofrecer del Otro y de la justicia solo puede ser expuesta mediante el lenguaje, el problema es que estos exceden al signo y, por lo tanto, también a la significación. La deconstrucción desde esta perspectiva aparece como una a-signación y como una des-marcación que a fin de evitar caer en el no lugar de una exterioridad absoluta (absuelta, no-representable) al enfrentarse a la hospitalidad, intenta moverse por las grietas ${ }^{10} \mathrm{y}$ por los límites, de ahí que su lectura resulte aporética: "Derrida intenta comprender el imperativo ético de la hospitalidad, pero lo que genera la deconstrucción de ese topos son conceptos límite, es decir, aporías o antinomias indecidibles" (Herrero, 2018: 8I). La aporía que nos interesa particularmente aquí aparece en la tensión entre el derecho y la justicia.

El análisis que desarrolla Derrida en Fuerza de ley deja ver los diferentes momentos de la relación entre el derecho con una fuerza o violencia que le sería propia, ${ }^{\text {"I }}$ formulando una compleja lectura de la relación entre el derecho y la justicia. El derecho se ampara en la fuerza de la autoridad, donde la justicia es un elemento foráneo que, aunque se encuentra desplazada del ámbito del derecho, al ser una noción que no presenta categorías, ni reglas, ni criterios comunes con él, es, sin embargo, la única que puede legitimarlo. ¿Una paradoja o la imposibilidad misma de relacionar el derecho con alguna justicia? Pregunta frente la cual el filósofo francés debe retroceder

\footnotetext{
${ }^{8}$ Acontece aquí uno de los tópicos liderados por Lévinas, la verdad como dependiente de la justicia.

9 Recordemos que para Lévinas este medio responde al logos desde una heterogeneidad irreductible. Puede verse desde aquí, aunque de lejos, un rasgo de la deconstrucción incoado en la tematización del ámbito del decir realizada por Lévinas (1987b: 48 y 86).

ro Cuestión que aprende del mismo Lévinas "-Verdad impensable de la experiencia viva a la que incesantemente vuelve Levinas, y que la palabra filosófica no puede intentar abrigar sin mostrar enseguida, en su propia luz, grietas lamentables [...] la escritura de Lévinas tiene esta propiedad, la de moverse siempre, en sus momentos decisivos, a lo largo de esas grietas, progresando con maestría mediante negaciones y negación contra negación. Su vía propia no es la de un «o bien... o bien», sino de un «ni... ni tampoco»" (Derrida, I989: 123)-, bajo la forma de una relación sin relación: "no se puede señalar que Derrida rompa definitivamente con Lévinas, ni que se acerque e identifique con su obra” (Biset, 2007: 137). Para tener otro ángulo de este pensamiento paradójico véase Penchaszadeh, 2011.

"Una violencia fundacional (Derrida, 1992: 139, I40, I49 y 16I), y una violencia conservadora o re-fundadora (Derrida, 1992: 167-I68).
} 
y afirmar que estos problemas "son infinitos, si se puede decir, en ellos mismos, porque exigen la experiencia de la aporía" (Derrida, 1992: I42).

Si la justicia fuera parte del derecho, si tomara parte en el acto performativo que funda, refunda, mantiene y aplica el derecho, quedaría parteada en la relación con aquella fuerza realizativa, interpretativa (Derrida, I992: 139), que termina (y empieza) irreductiblemente en la violencia. Es por eso que la justicia "debe" quedar absuelta de ello. La posibilidad de la justicia se funda en una experiencia de la aporía, no asimilable por el derecho. ${ }^{12}$ La comparación aporética del derecho y la justicia se mueve "alternadamente en el terreno de lo posible y de lo imposible" (Penchaszadeh, 20II: 257). Esta relación puede ser abordada como una exigencia mutua, pero sin una regla lógica que la subsuma. ${ }^{13}$ Como cálculo, el derecho debe procurar la justa aplicación de una regla a un caso particular, por medio de un juicio determinante (subsumir bajo leyes, enjuiciar), pero nunca este derecho per se puede cuestionar, ni su proceso, ni sus reglas, ni sus principios, ni, por lo tanto, auto legitimar sus juicios. Su cálculo se realiza $-\mathrm{y}$ esto es solo la pretensión que persigue el pensar la justicia- en relación de una justicia que aparece aquí como incalculable. ${ }^{14}$

La justicia se asemeja al espectro que deambula sin quedar atrapado en una lógica oposicional, ni en la oposición de fuerzas diferenciales (Derrida, 1992: I33). La diferencia y el espectro operan con la misma "lógica". Las decisiones tomadas en nombre del derecho asumen responsabilidades, que serán reclamadas desde un discurso no dicho que visibiliza el orden de la política y de la razón desde una justicia en suspenso, indecible e incognoscible por ilimitada. ${ }^{15}$ Es por ello que la aporía tiene una compleja relación con la idea derrideana de fantasma. ${ }^{16}$ Toda decisión, jurídica o ética, tendría su secreta disonancia respecto de un fantasma (Derrida, 1992: 150)

\footnotetext{
I2 "Quiero insistir inmediatamente en reservar la posibilidad de una justicia, es decir de una ley que no solo excede o contradice el derecho, sino que quizás no tiene ninguna relación con el mismo o mantiene una relación tan extraña que lo mismo puede exigir el «droit» que excluirlo" (Derrida, 1992: 131).

г3 "Todo sería todavía simple si esta distinción entre justicia y derecho fuera una verdadera distinción, una oposición cuyo funcionamiento está lógicamente regulado y sea dominable. Pero sucede que el derecho pretende ejercerse en nombre de la justicia y que la justicia exige instalarse en un derecho que exige ser «enforced». La deconstrucción se encuentra siempre entre los dos" (Derrida, I992: I48).

is "Cada vez que aplicamos una buena regla a un caso particular, a un ejemplo correctamente subsumido, según un juicio determinante, podemos estar seguros de que el derecho encuentra su lugar, pero no la justicia, ciertamente. El derecho no es la justicia. El derecho es el elemento del cálculo y es justo que haya derecho; la justicia es incalculable, exige que se calcule con lo incalculable; y las experiencias aporéticas son experiencias, tan improbables como necesarias, de la justicia, es decir, momentos en que la decisión entre lo justo y lo injusto no está jamás determinada por una regla" (Derrida, i992: I42).

${ }^{15}$ Estos tres elementos pueden observarse en los tres ejemplos de la aporía ofrecidos por Derrida (I992: I48, I50 y I52).

${ }^{16}$ La diferencia y lo espectral aparecen temáticamente relacionadas en el pensamiento de Derrida desde i968, cuando escribe La Différance, hasta 1993, cuando escribe Los espectros de Marx. Este último texto asume el dilema hamletiano, mostrando un tiempo que aparece fuera de quicio, dislocado por el espectro que produce una "disyunción temporal" (Derrida, 1995: 31).
} 
que se aparece entre las fuerzas diferenciales que se oponen y que se descimbran por la deconstrucción:

La justicia está más allá de la positividad mecánico-gramatológica del derecho [...] El origen no dialectizable es lo indiferenciado que da lugar a la diferenciación. En el escrito Fuerza de ley apunta a una fundamentación translegal, transgrafológica del derecho, que reivindica el carácter propio de lo político: tener que decidir. Se trata en él de juzgar aquello que permite juzgar, aquello que autoriza el juicio. La justicia es, en este sentido, la deconstrucción. (Herrero, 20I8: 83).

En Violencia y metafísica Derrida entiende el lenguaje como «economía de violencia»: "el lenguaje no puede jamás sino tender indefinidamente hacia la justicia reconociendo y practicando la guerra en sí mismo. Violencia contra la violencia" (1989: 157). Ante lo cual, cuando el Otro levinasiano aparece en el lenguaje, lo hace a partir de leyes y categorías que traicionan su propia alteridad. El Otro no puede ser dicho, es completamente no-representable, solo puede hablársele:

No podré hablar de otro, convertirlo en tema, decirlo como objeto, en acusativo. Solamente puedo, solamente debo hablar a otro, llamarle en vocativo, que no es una categoría, un caso de la palabra, sino el surgimiento, la elevación misma de la palabra. Es necesario que falten las categorías para que no se falte al otro; pero para que no se falte al otro, es necesario que éste se presente como ausencia y aparezca como no-fenomenalidad. (Derrida, 1989: 139).

Para Derrida (I989: I23), la otredad levinasiana como "«cara a cara sin intermediario» ni «comunión»" manifiesta la verdad de nuestra relación con el Otro, "la verdad ante la que el logos tradicional es para siempre inhospitalario" (Derrida, 1989: I23). La posibilidad que tiene aquí la alteridad levinansiana de ser no-representable — como heterogeneidad al logos y a su violencia constitutiva- es nula:

Un ser sin violencia sería un ser que se produjera fuera del ente: nada; no-historia; noproducción; no-fenomenalidad. Una palabra que se produjera sin la menor violencia no de-terminaría nada, no diría nada, no ofrecería nada al otro; no sería historia y no mostraría nada; en todos los sentidos de esta palabra, y en primer lugar en su sentido griego, sería una palabra sin frase. (Derrida, 1989: 20I).

Tanto el Otro como la justica no pueden ser representados. En este sentido la hospitalidad sostiene la posibilidad de ambos. El Otro y la justicia -en tanto que no-representables, en tanto que no se dejan decir- hallan en la hospitalidad una fórmula ético-política más allá de la violencia del lenguaje (y del derecho). En esta órbita es que entendemos, al mismo tiempo, la necesidad de la deconstrucción de las condicionalidades (señaladas por Biset) y la indeconstructibilidad de la justicia que propone Herrero (2018: 82-83). De esto último se sigue que la deconstrucción se detiene, anulándose delante de la justicia. Desde nuestro punto de vista esto sucede porque es 
heterogénea a ella, siguiendo con Lévinas a Platón (República 509b) decimos es un عĩdos que, como el Bien, se eleva más allá de la esencia (epékeina tes ousías): ${ }^{17}$

El problema ante el cual se encuentra el pensamiento derridiano, una vez que ha alcanzado la situación de la razón desconstruida, es la imposibilidad de «decir» y de «decidir» definitivamente ese ámbito. La deconstrucción opera desde una idea de justicia infinita. (Herrero, 2018: 84).

La salida política que busca Herrero a la aporía derrideana de la hospitalidad es hallada en la decisión. Esa salida sigue las tres aporías que desarrolla Derrida en Fuerza de ley. Así las expone Herrero:

$\mathrm{I}^{\mathrm{a}}$ Para poder juzgar con justicia hay que reinstaurar la ley [...] juzgar su justicia; [...] toda decisión que pretenda ser justa debe seguir y no seguir al mismo tiempo la regla. $2^{\underline{a}}$ Ninguna justicia se hace derecho sin una decisión que dirima: ha de afrontar lo indecidible, ha de afrontar «la experiencia de lo que siendo extranjero, heterogéneo con respecto al orden de lo calculable y de la regla, debe, sin embargo entregarse a la decisión imposible, teniendo en cuenta el derecho y la regla» (Derrida, 1998a: 55). $3^{\mathrm{a}}$ Por muy no presentable que sea la justicia, una decisión justa se requiere inmediatamente y, aunque se tuviera tiempo para decidir, hay un salto entre la argumentación teórica y el momento de la decisión... (Herrero, 2018: 84).

En la segunda entonación (señalada por Biset) que presenta Derrida sobre la hospitalidad como irreductible, se lee que "el problema radica en cómo construir un orden político en función de esa hospitalidad" (Biset, 2007: 139). El mismo problema es el que trata Herrero, como una salida ético-política de la aporía que presenta la reflexión derrideana sobre la hospitalidad. La lectura de Herrero da cuenta de un Derrida que asume "lo político como decisión y como apertura a la pura alteridad, al Otro, en el centro de toda realidad práctica" (Herrero, 20I8: 85), al tiempo que acepta que la separación es la condición de posibilidad (y de imposibilidad) del amigo político que viene (del exterior), problematizando el cómo fundar una política de la separación, a partir de una éticapolítica de la hospitalidad. Como veíamos, aunque la deconstrucción opere desde una idea de justicia infinita, esto "no debe llevar a la inactividad política, puesto que aunque no sea presentable [la justicia], siempre es posible: la justicia incalculable ordena calcular" (Herrero, 20I8: 84). Ante lo cual Herrero pregunta "¿qué camino deja a la acción esta propuesta, sino el de la voluntad de poder?" (2018: 84), evidenciando nuevamente la presencia de la aporía. Como si en el límite de la deconstrucción surgiera inmediatamente $-\mathrm{y}$ aquí la inmediatez se queda corta- aquella fuerza/violencia originaria de la cual emerge la voluntad de poder:

La operación que consiste en fundar, inaugurar, justificar el derecho, hacer la ley, consistiría en un golpe de fuerza, en una violencia realizativa, y por tanto interpretativa, que no es justa o injusta en sí misma. [...] El discurso encuentra ahí su límite: en sí mismo, en su poder realizativo mismo. Es lo

\footnotetext{
${ }^{17}$ "A las cosas cognoscibles les viene del Bien no solo el ser conocidas, sino también de él les llega el existir y la esencia, aunque el Bien no sea esencia, sino algo que se eleva más allá de la esencia en cuanto a dignidad y a potencia" (Platón, 1988: 334)
} 
que aquí propongo llamar [...] lo místico. Hay un silencio encerrado en la estructura violenta del acto fundador. (Derrida, 1998a: 33).

En esta cita propuesta por Herrero se omite la última parte del texto: "Hay un silencio encerrado en la estructura violenta del acto fundador. Encerrado, emparedado, porque este silencio no es exterior al lenguaje" (Derrida, I992: I39). Nos enfrentamos aquí a un nudo complejo, en que se tensan el límite del discurso, un silencio interior al lenguaje, lo místico y la estructura violenta del acto fundador. No es el acto fundador el violento, sino la estructura en la cual se ve forzado a materializarse, —otra vez- el lenguaje (y su fuente lógico-legal, heterogénea a la hospitalidad ética).

En síntesis, Derrida rechaza la separación metafísica, pero acepta la separación política sin dejar de lado la posibilidad de la ética de la hospitalidad. Puede que en este contexto el Otro levinasiano quede como disimulado, pues aún sigue habiendo un silencio encerrado, lo que trae a tema el ahogo y la necesidad de evasión que sufre la identidad del Mismo en Lévinas, lo que resuelve tratar mediante la substitución (Substitution) (Lévinas, 1987b: 163); ${ }^{18}$ cuestión que retomaremos en el segundo apartado.

\section{EL OTRO COMO POSIBILIDAD DE LA HOSPITALIDAD ILIMITADA}

\section{LA ONTOLOGÍA POLÍTICA DE LA TENSIÓN}

La relación en que Lévinas expone la hospitalidad respecto de la metafísica es fundamental para entender su planteamiento ético. El logos, limitado en su identidad finita — por más que sea esta la de la totalidad-, solo puede pensar lo infinito cuantitativamente (calculando). Esta disputa sugiere una interpretación especial de la antigua polémica entre lo discreto y lo continuo. La diferencia -o separación — radical que postula Lévinas entre el Mismo y el Otro no puede llegar a ser subsumida bajo las categorías lógicas en las que opera la ontología occidental, puesto que esta suprime la referida separación absoluta entre el Mismo y el Otro. ${ }^{19}$ La anarquía de la proximidad en que

\footnotetext{
${ }^{18}$ Herrero da cuenta de esta categoría en el apartado IV de su texto Ética de la hospitalidad: la lógica de la sustitución, sugiriendo con De Ville que es desde aquí que Derrida se aparta de Lévinas, hacia una concepción mesiánica de la hospitalidad. Herrero no problematiza el problema del silencio, ni de la huella de Lévinas en Derrida tal como intentamos pensarlo aquí. La solución que propone exhibe un giro programático — un giro antropológico, típico ante los problemas metafísicos de este calibre, que enhebra a su modo el escepticismo y las necesidades prácticas que hay que resolver siempre iya!- en el cual la deconstrucción debe dar paso a la acción política mediante una decisión ético-política. Herrero remite la "sustitución" a Totalidad e infinito y De otro modo que ser, o más allá de la esencia, sin embargo, en la primera de estas no aparece sino en el sentido convencional, y no se refiere a lo que Lévinas intenta decir en De otro modo que ser.

19 "El metafísico y lo Otro no constituyen alguna correlación reversible. La reversibilidad de una relación en la que los términos se leen indiferentemente de izquierda a derecha y de derecha a izquierda, los acoplaría, uno al otro. Se complementarían en un sistema, visible desde fuera. La pretendida trascendencia se reabsorbería así en la unidad del
} 
Lévinas (1987b: 165) piensa la relación ética, se traduce en la falta de un principio lógico, en el que lo diferente pueda ser identificado: "la diacronía es el rechazo de la conjunción, lo no-totalizable, y en este preciso sentido infinito" (1987b: 55 ).

La relación ética con el Otro en Lévinas se produce - fuera del horizonte del ser y el logos- en una exterioridad infinita. La metafísica del Otro aspira a ser la única absolución posible ante una sincronización determinada a partir de las leyes de la economía de lo real. ${ }^{20}$ En esto puede insertarse la dificultad que enfrenta la aporía de la hospitalidad derrideana, en vistas a pensar una hospitalidad ilimitada sin la separación metafísica. Quizá sea esa dificultad la causa que provoca que la tensión que existe en los textos de Derrida entre violencia y justicia nunca se resuelva (Guille, 2015: 268; Biset, 2012). La separación absoluta tiene una difícil relación con la aporía de la hospitalidad derrideana. Como mínimo ambas se articulan de manera especial con algo infinito. ${ }^{21}$ La deconstrucción derrideana, al no asumir categorías absolutas, deja abierta la posibilidad de una hospitalidad ilimitada, sin fundarla en categorías metafísicas, pero abierta a una lectura aporética. Lo cual puede ser considerado uno de los grandes méritos de la deconstrucción derrideana; pensar con el logos aquello que este no puede pensar: sus grietas.

El problema del extranjero en Derrida y el Otro levinasiano se articulan de manera similar, descoyuntándose de y excediendo a, respectivamente, una política y una razón, que no pueden darles un trato justo, ni aprehenderlos en su alteridad, de manera que, no pudiendo atender a su radical extrañeza (Arnaiz y González, 1998: I2I), no les queda más que ponerlos (traducirlos) en los esquemas de lo propio, de la soberanía del Mismo y la racionalidad económica en que este se mantiene. Todos somos extranjeros para el Otro e, inclusive, en cierto sentido también para nosotros mismos. La primera violencia para con el extranjero consiste, según Derrida, en la imposición de traducción de su lengua por parte de la casa, del anfitrión, del rey, del poder, del Estado, etc., con lo que se da pie a la aporética relación del lenguaje y el extranjero, pues ¿si el

sistema que destruiría la alteridad radical de lo Otro. La irreversibilidad no significa solamente que el Mismo va hacia lo Otro, de distinto modo que lo Otro va hacia el Mismo. Esta eventualidad no se considera: la separación radical entre el Mismo y lo Otro significa, precisamente, que es imposible colocarse fuera de la correlación del Mismo y de lo Otro para registrar la correspondencia o la no correspondencia entre este ir y este retorno. En este caso el Mismo y lo Otro se encontrarían reunidos bajo una mirada común y la distancia absoluta que los separa sería suprimida" (Lévinas, 1987a: 60). Esta mirada común bajo la cual el mismo y el otro serían reunidos puede ser relacionada de una manera singular con la hipótesis del tercer hombre; manifestando una relación especial respecto del problema del observador.

20 "La totalidad se constituye económicamente [...] Vemos así que el concepto de totalidad hegeliana es reinterpretado desde la economía. Pero la relación fundante del «cara a cara» exterior a la totalidad y a la economía es el fundamento absoluto y sin equívocos de esta moral" (Guillot, D. en Lévinas, 1987a: 23-24).

${ }^{21}$ Esos problemas "son infinitos, si se puede decir, en ellos mismos, porque exigen la experiencia de la aporía, la cual no es ajena a lo que acabo de denominar lo místico" (Derrida, I992: I4I-I42). Por aquí puede relacionarse la justicia ilimitada ¿o infinita? - a la que se refiere Derrida, y la idea de infinito en que se sustenta Totalidad e infinito: "La noción levinasiana de la justicia se acercaría más bien al equivalente hebreo de lo que nosotros traduciríamos quizás como santidad" (Derrida,I992: I48). 
extranjero ya hablase nuestra lengua, con todo lo que esto implica, sería todavía extranjero? (Derrida, 2008: 23).

La pregunta de la hospitalidad comienza ahí: ¿debemos exigir al extranjero comprendernos, hablar nuestra lengua en todos los sentidos de este término, en todas sus extensiones posibles, antes y a fin de poder acogerlo entre nosotros? (Derrida, 2008: 2I-23).

Esta compleja situación de la necesidad de traducción - que abre la aporía de La Hospitalidad - contrasta con la experiencia pura del Otro, o experiencia absoluta, que plantea Lévinas. ${ }^{22}$ En este difícil nudo que tienen en común ambos planteamientos, vemos una intención de rescatar la singularidad, a partir de su separación y diferencia, cuyo contexto es el de una posible heterogeneidad (del Otro, del extranjero o de la justicia), haciéndose cargo, responsablemente, de las dificultades que ahí acontezcan. En el pensamiento de Lévinas, la comprensión de la subjetividad que proporciona la ontología occidental implica una anulación similar a la violencia de traducción:

La violencia no consiste tanto en herir y aniquilar como en interrumpir la continuidad de las personas, en hacerles desempeñar papeles en los que ya no se encuentran, en hacerles traicionar, no solo compromisos, sino su propia sustancia. (Lévinas, 1987a: 47-48).

\section{LA HOSPITALIDAD: UNA EXPERIENCIA ILIMITADA DEL OTRO}

Puede leerse, a partir del pensamiento de Lévinas, que el desarrollo lógico del pensamiento occidental ha quedado clausurado en el Mismo, lo que solo podría ser superado en el "medio" de una relación ética que fuese pura recepción, hospitalidad ilimitada ante una alteridad totalmente otra. Solo ahí el Mismo se descubre o absuelve del estar clavado en lo propio, de la clausura del en casa. La "dialéctica levinasiana" no va del Mismo al Otro, sino que viene de un Otro, que fisura el solipsismo del Mismo, abriéndolo a lo trascendente, pero no al conocimiento absoluto, sino a la experiencia pura e inédita de lo infinito. La hospitalidad ética levinasiana se desarrolla en un medio que no es ni el ser ni el logos —ni la economía, ni la ley política, por cierto-. Es un no-lugar el que, dando pie a la revelación del Otro, posibilita la hospitalidad ilimitada. La relación ética puede pensarse, tal como la entiende Lévinas, como el desgarro de una comunidad legislada desde la autosuficiencia de una razón política elaborada desde su identidad soberana, que se determina únicamente a partir de sí misma.

\footnotetext{
${ }_{22}$ "La experiencia absoluta no es develamiento. Develar, a partir de un horizonte subjetivo, es ya perder el noumenos. Solo el interlocutor es el término de una experiencia pura en la que el otro entra en relación, al mismo tiempo que permanece $\kappa \alpha \theta^{\prime} \alpha \dot{v} \tau o ́$; en la que se expresa sin que tengamos que develarlo a partir de un «punto de vista», en una luz prestada. La «objetividad» que busca el conocimiento plenamente conocimiento, se realiza más allá de la objetividad del objeto. La que se presenta como independiente de todo movimiento subjetivo es el interlocutor cuya modalidad consiste en salir de sí, en ser extranjero..." (Lévinas, 1987a: 9o).
} 
El Otro se aborda compadeciéndose de él, poniéndose en su lugar, como substitución. ${ }^{23}$ Posiblemente sea este uno de los puntos más difíciles de afrontar en el pensamiento de Lévinas donde podría encontrarse la posibilidad de la hospitalidad ilimitada-, porque para ponerse en el lugar del Otro, en el esquema de una separación absoluta, hay que dejar de lado todo lo que se es, todo lo que soy. En este ponerse en el lugar del Otro, o substitución, se desquicia la temporalidad del Mismo, posibilitando la exterioridad de lo totalmente otro. La substitución viene a superar la violencia del lenguaje. El Otro se resiste pacíficamente — sin hacer nada - a ser interpretado, a ser traducido. El significado del decir del Otro es experiencia directa del Otro, sin mediaciones lógicas, universales, ni leyes. El lenguaje guarda la posibilidad de la violencia, en tanto que no puede decir al Otro; pero también es la condición de posibilidad para la hospitalidad ilimitada, pues le permite expresarse:

La diferencia absoluta, inconcebible en términos de lógica formal, solo se instaura por el lenguaje. El lenguaje lleva a cabo una relación entre los términos que rompen la unidad del género. Los términos, los interlocutores, se absuelven de la relación o siguen siendo absolutos en la relación. El lenguaje se define tal vez como el poder mismo de romper la continuidad del ser o de la historia. (Lévinas, 1987a: 208). ${ }^{24}$

Este desgarro que produce el Otro en el tejido de lo real y de las leyes instaura la necesidad de una política del encuentro, donde se juegue la verdad de la experiencia política, que será siempre la experiencia del Otro. Como hospitalidad que da sentido ético a la sociabilidad, la experiencia del Otro será siempre una experiencia inédita, una comunicación que permite la comunidad de tiempos y experiencias diferentes, no subsumibles bajo categorías o leyes que las sistematicen en cálculos ni esquemas finitos. Fuera del clima ético de la hospitalidad ilimitada, el lenguaje siempre será dominado por el interés:

El interés del ser se dramatiza en los egoísmos que luchan unos contra otros, todos contra todos, en la multiplicidad de egoísmos alérgicos que están en guerra unos con otros y, al mismo tiempo, en conjunto. La guerra es el gesto o el drama del interés de la esencia. (Lévinas, 1987b: 46-47).

El más allá de la totalidad que procura Lévinas para la relación ética, viene a preparar la irrupción de un nuevo personaje en el drama de la guerra, el cual se revela desde la exterioridad del

\footnotetext{
${ }^{23}$ El otro no puede ser dicho, su palabra no es la del logos, por lo que tampoco puede ser interpretada desde lo universal. Solo se le puede acoger al otro, en la propia sensibilidad. Interpretarlo desde los esquemas del mismo es reducirlo, violentarlo (Lévinas, 1987b: 48 y 163).

24 "Desde la gramática y desde la lógica formal, el lenguaje es un sistema de signos gobernado por leyes internas que transmiten significaciones; tales significaciones intercambian neutralmente informaciones y mensajes en agrupaciones de signos gobernados por la lógica del ser. Es lo que Lévinas llama, en De otro modo que ser, o más allá de la esencia, ámbito de «lo Dicho», participio pasivo que sugiere una sedimentación lingüística ya codificada por la lexicografía en los diccionarios, en la cual se opera con un código clausurado sobre sí. Pero el mundo de las significaciones solo es tal, en un medio de significancia — «el Decir»-que, no solo genera los significados establecidos, sino que los desborda y rodea produciendo fisuras que aún conservan la huella del decir y permiten romper el lenguaje para salir por él fuera de él" (Pintor-Ramos, en Lévinas, 1987b: 32).
} 
Mismo para instaurar la Paz. Desde este nuevo personaje, el argumento de aquel drama queda referido a una conciencia idéntica, sorda y muda ante el Otro, produciendo un ahogo del espíritu. ${ }^{25}$ Una subjetividad sofocada y sofocante que, mientras se anexa la subjetividad y la humanidad del Otro por medio de una ley política hostil, tematiza la necesidad de la salida del drama de la guerra, en el cual el Mismo se halla como en lo suyo propio, en casa. El más allá de una ley política que limita lo ilimitado, es un preludio de la irrupción del Otro, que instaura la paz y el fundamento ético de la responsabilidad. La solución del drama queda puesta como "positividad de la responsabilidad que, fuera de la esencia, traduce el Infinito invirtiendo las relaciones y los principios, revocando el orden del interés" (Lévinas, 1987b: 56). Este modo de pensar perfila la necesidad de una tematización que no busca eliminar el ser (ni al Estado, ni a la política), sino comprenderlo a partir de lo otro que el ser (Lévinas, 1987b: 6r). La diacronía del Otro trae una nueva sincronía que surge ya no del tiempo histórico, sino de un tiempo ético:

El carácter excepcional, extra-ordinario, trascendente de la bondad depende justamente de esta ruptura con el ser y con su historia. Reconducir el bien al ser, a sus cálculos y a su historia es anular la bondad [...] La bondad da a la subjetividad su significación irreductible. (Lévinas, 1987b: 63-64).

Esta forma de comprender la subjetividad, desde la diferencia de su significación irreductible, y en su relación metafísica con un tercero - que refiere a la Idea del Bien-, nos deja ver el difícil fondo del pensamiento de Lévinas, en el que se articula la posibilidad (siempre aporética) de una hospitalidad ilimitada.

\section{CONCLUSIONES}

La comprensión ética de la relación con el Otro implica que el sujeto se halla inmerso en esa relación antes de ser-sujeto. El sujeto le debe su subjetividad a Otro. Desde aquí puede verse el lazo entre intersubjetividad e interdependencia. Hoy más que nunca los conflictos amenazan de pronto a cualquiera con convertirlo en lo extranjero, en el propio país, en la propia "casa". La urgencia de las medidas requeridas por la crisis social global hace que estas deban llegar a transgredir el margen de la racionalidad soberana.

El límite que la deconstrucción descubre en la comprensión de la racionalidad lógica es similar a la exigencia de ese más allá que merodea siempre al pensar filosófico y que, como espectro o fantasma, estimula una comprensión, una acción y una crítica por la cual se reclama la necesidad

25 "Es necesario preguntarse desde ahora si este ahogo o esta retención no es la posibilidad extrema del espíritu, portador de un sentido para lo más allá de la esencia" (Lévinas, 1987b: 47). 
de que las cosas retornen a un lugar en que no tenga espacio la injusticia. La hospitalidad ilimitada suspende la enorme gesta del ser y de la historia, las leyes políticas, los razonamientos y los juicios; a fin de atraer la posibilidad de la paz.

El éxodo de la continua fuga del sí mismo solo se colma en la hospitalidad, en una relación previa al cálculo racional. La relación ética de hospitalidad debiera ser la base de cualquier forma social, política o económica, puesto que estas solo a partir de esa modalidad pueden aproximarse al ideal de justicia. Hay en ello una intención, una subjetividad que se abre desde su fondo a una comunicación previa a la lengua, previa a la cultura, en una anarquía del lenguaje y de los significados, que económicamente se intercambian en la comunicación. Desde esta previedad anárquica es posible la fisura del tiempo, de la economía y de la historia, hacia una comprensión que reconstruye la economía de la comunicación y del lenguaje, quedando de ese modo aquellas formas expuestas en el contexto de la posibilidad de la superación de los límites del yo y de su soberanía. La hospitalidad, como la superación del interés del Mismo, implica una re-comprensión del concepto de lo propio, hasta su re-comprensión como interés común, en una política de interdependencia. Si asumimos que la hospitalidad es un evento de des-apropiación respecto del Otro, de mi lenguaje e inclusive quizá de sí mismo — como posibilidad de una relación de desapropiación mutua - se ve como la identidad se desfonda para ser reformulada con justicia en el medio de una relación que no la deja clausurada a su finitud.

\section{RECONOCIMIENTOS}

Este artículo forma parte del Proyecto del Fondo Nacional de Desarrollo Científico y Tecnológico (FONDECYT) de Iniciación en Investigación $\mathrm{N}^{\mathrm{o}}$ III708I2.

\section{REFERENCIAS}

González, Graciano. "La condición de extranjero del hombre. Apuntes para una ética de la diferencia", Logos 32 (1998): I2I-I44. Disponible en https://cutt.ly/2mGWdLX

Biset, Emmanuel. "Jacques Derrida, entre violencia y hospitalidad", Daimon 40 (2007): I3I-I44. Disponible en https://cutt.ly/WmGWkty

Biset, Emmanuel.Violencia, justicia y política. Una lectura de Jacques Derrida. Córdoba: Eduvin, 2012.

Derrida, Jacques. Violencia y metafísica. Ensayo sobre el pensamiento de Emmanuel Lévinas. En La escritura y la diferencia. Barcelona: Anthropos, 1989. 
Derrida, Jacques. "Fuerza de ley: El Fundamento místico de la autoridad", Doxa ir (I992): I29-I9I. https://doi.org/IO.I4198/DOXAig92.II.06

Derrida, Jacques. Espectros de Marx. El estado de la deuda, el trabajo del duelo y la nueva internacional. Madrid: Trotta, 1995 .

Derrida, Jacques. Fuerza de Ley. Madrid: Tecnos, 1998a.

Derrida, Jacques. Adiós a Emmanuel Lévinas. Palabra de Acogida, Madrid: Trotta, 1998b.

Derrida, Jacques. De la gramatología. Buenos Aires, Siglo XXI, 2008.

Derrida, Jacques; Dufourmantelle, Anne. La hospitalidad. Buenos Aires: La Flor, 2008.

De Ville, Jacques. Jacques Derrida: Law as Absolute Hospitality. London: Routledge, 20II.

Guille, Gustavo. "Las aporías de la hospitalidad en el pensamiento de Jacques Derrida", Eukasia 64 (2015): 265-278. Disponible en https://cutt.ly/JmGWQbO

Herrero, Montserrat. "Políticas de la hospitalidad en el pensamiento de Jacques Derrida", Revista de Estudios Políticos I80 (2018): 77-I03. https://doi.org/10.18042/cepc/rep.I80.03

Korstanje, Maximiliano. "Pensando la hospitalidad", Revista de la Facultad de Ciencias Sociales y Jurídicas de Elche I/II (2016): 208-2I4. Disponible en https://cutt.ly/4mGWE3p

Lévinas, Emmanuel. Totalidad e infinito. Ensayo sobre la exterioridad. Salamanca: Ś́gueme, 1987a.

Lévinas, Emmanuel. De otro modo que ser, o más allá de la esencia. Salamanca: Sígueme, 1987b.

Penchaszadeh, Ana. "Política, don y hospitalidad en el pensamiento de Jacques Derrida", Revista de Filosofía Moral y Política 44 (20II): 257-271. https://doi.org/ı0.3989/isegoria.20II.i44.729

Penchaszadeh, Anna; Sferco, Senda. "Solidaridad y fraternidad. Una nueva clave ético-política para las migraciones", Revista Interdisciplinar da Mobilidade Humana 27/55 (2019): 149-164. https://doi.org/I0.1590/1980-85852503880005510.

Platón. República. En: Diálogos IV. Madrid: Gredos, 1988. 